\title{
Skeletal lead-210 as an index of exposure to radon decay products in mining
}

\author{
F A FRY, J L SMITH-BRIGGS, AND M C O'RIORDAN \\ From the National Radiological Protection Board, Chilton, Didcot, Oxon OX11 ORQ, UK
}

ABSTRACT Exposure to radon-222 and its short-lived decay products in mines results in increased bone content of lead-210 in miners. Cumulative exposure is usually determined from air measurements underground. It may also be inferred from radiochemical measurements on bone samples. We describe how this is achieved, illustrate the degree of agreement between the two methods for a particular case, and discuss some qualifications.

Miners may be exposed to high levels of radon-222, a naturally occurring radioactive gas, because of poor ventilation underground. The short-lived solid decay products of the gas are also radioactive, and they form a radioactive aerosol, which causes irradiation of the lung and may induce lung cancer. Exposure of miners to the short-lived decay products is usually monitored by measurements in the workplace. Personal monitoring is not practised widely because of technical and economic impediments.

One of the later decay products of the gas, the long-lived radionuclide lead-210, may, in principle, be used as an indicator of cumulative exposure. ${ }^{1-3}$ After uptake to blood, lead-210 is deposited primarily in bone, liver, and kidneys, but is tenaciously retained only in bone. Its concentration in bone may therefore be used to estimate the exposure accumulated over a period. The mean retention time in other tissues is shorter, and their lead-210 content does not reflect long-term exposure.

We recently had occasion to determine lead-210 in postmortem samples of bone from a miner and to infer his exposure from the results. We could also estimate his exposure from past measurements in the mine in which he worked. We report here on the degree of agreement between the two approaches and the qualifications that must be attached to it.

\section{Normal concentrations}

Since radon-222 and its decay products occur everywhere, the whole population is exposed to them both by inhalation and ingestion. For non-smokers, consumption of food is usually the most important route of intake. The concentration of lead-210 in bone

Received 25 January 1982 Accepted 23 March 1982 depends on sex, age, and diet; thus the normal concentrations in members of the public may be expected to vary widely.

Only limited information is available on these normal concentrations. UNSCEAR ${ }^{4}$ quotes a value of $4 \mathrm{mBq} / \mathrm{g}$ in bone ash for the United Kingdom, and values for other island locations range from 2 to 8 $\mathrm{mBq} / \mathrm{g}$. Concentrations in continental populations may be somewhat higher, and values as high as 12 $\mathrm{mBq} / \mathrm{g}$ have been reported. Allowance must be made for this background level when assessing that due to occupational exposure.

\section{Experimental procedure}

It is possible to determine lead- 210 by direct measurement of the low-energy photons that it emits, but this physical method was not sensitive enough here. A radiochemical procedure was used instead, although it is quite time consuming.

The method used was based on an analycical technique ${ }^{5}$ in which lead-210 is extracted as a lead sulphate precipitate in a form suitable for measuring the beta-particle emission of its decay product bismuth-210.

The bone marrow and soft tissue were removed from a section of the femur, and the bone sample was then dissected into small pieces. About $100 \mathrm{~g}$ was slow-ashed at $500^{\circ} \mathrm{C}$ over seven days. The residue was dissolved in concentrated nitric acid, the solution taken to dryness, and the resulting powder reashed at $500^{\circ} \mathrm{C}$ over four days.

Three aliquots of the bone ash were taken, and lead carrier in the form of $\mathrm{Pb}\left(\mathrm{NO}_{3}\right)_{2}$ was added to each. After dissolution of each aliquot in hydrobromic acid, lead and bismuth ions were isolated from other ions by a solvent extraction technique. The lead was then separated from bismuth by the formation of the 
insoluble $\mathrm{BiOCl}$ compound; repetition of this process ensured complete separation. Lead was then precipitated as a lead sulphate complex. The overall yields of the separation process were estimated gravimetrically to be about $50 \%$ on average.

The lead- 210 activity was determined by counting the beta-particle emission from bismuth -210 after a delay of about four weeks to allow this radionuclide to grow into secular equilibrium with its precursor.

\section{Results and interpretation}

The mean activity concentration in the bone ash and the standard deviation were $22 \pm 8 \mathrm{mBq} / \mathrm{g}$. The small spread illustrates the reproducibility of the radiochemical procedure. Other analytical uncertainties are smaller: uncertainties in the counting process due to the random nature of radioactive decay are about $4 \%$, and the uncertainty due to calibration procedures does not exceed about $10 \%$.

The lead-210 content is clearly raised above the level in the general population. If we use the UNSCEAR value for the United Kingdom the excess is $18 \pm 8 \mathrm{mBq} / \mathrm{g}$.

Occupational exposure to radon-222 and its shortlived decay products is usually expressed in working level months (WLM). A working level (WL) is defined as any combination of the short-lived decay products of radon-222 in one litre of air that will result in the ultimate emission of $1.3 \times 10^{5} \mathrm{MeV}$ of potential alpha energy during decay to lead-210. Thus inhalation of air at a concentration of $1 \mathrm{WL}$ for 170 hours, a working month, results in an exposure of one working level month (1 WLM).

We used the model of Eisenbud et $a l^{6}$ to infer the exposure to radon decay products that would result in the excess concentration of lead-210 in bone. They calculated a value of $0.3 \mathrm{~Bq}$ of skeletally deposited lead-210 per WLM of exposure. If, with them, we assume that the retention of lead-210 in bone can be expressed by a single exponential function with an effective half life of 110 months, it can be shown that the total activity A of skeletal lead-210 may be expressed as:

$$
A=0.3 N \int_{0}^{t_{1}} \exp \left(\frac{0.693 t}{110}\right) d t \times \exp \left(\frac{0.693 t_{2}}{110}\right) B q
$$

where $\mathrm{N}$ is the average exposure, WLM per month;

$t_{1}$ is the duration of exposure, months;

$t_{2}$ is the time since last exposure, months.

In the case that we were considering, $\mathrm{t}_{1}$ was about 260 months and $t_{2}$ almost 12 months, so that the foregoing expression reduces to:

$$
\mathrm{A}=37 \mathrm{~N} \mathrm{~Bq}
$$

The total weight of bone in an adult $\operatorname{man}^{7}$ is about $5000 \mathrm{~g}$ and the ash weight about $2700 \mathrm{~g}$; the skeletal activity concentration is thus $14 \mathrm{~N} \mathrm{mBq} / \mathrm{g}$, when expressed in terms of ash weight.

From the excess lead- 210 of $18 \pm 8 \mathrm{mBq} / \mathrm{g}$ in the ash sample, we therefore inferred an average exposure of $(1.3 \pm 0.5)$ WLM per month, or an average of $(15 \pm 6)$ WLM a year for the two decades or so that the miner had worked underground.

\section{Mine measurements}

During the second decade of the miners' exposure, about 300 measurements of radon-222 and the shortlived decay products were made on 17 separate occasions in the mine in question. All but one of the sets of measurements were made in the last three years of the decade. Samples of air were most often taken at eight locations, but four more substantial surveys involved about 50 locations on the average and on one occasion more than 100 . On most occasions the gas was measured with scintillation flasks, and the concentration of decay products was deduced for the prevailing state of ventilation, but the decay products were measured directly by the modified method of Kusnetz in some major exercises. ${ }^{8}$

The simplest way to estimate the exposure of miners is to multiply the mean concentration for the mine (in WL) by 12, the number of months in the year. Another way is to weight the answer for the fraction of the shift spent at the location of the measurement. The former tends to overestimate, because WL values tend to be higher in working localities than elsewhere, whereas the latter tends to underestimate because the exposure incurred for the rest of the shift underground tends to be ignored. It is possible to correct the weighted values in a crude fashion. Data from the surveys suggest that the time spent at a workplace was generally about 6.5 hours a shift. For another hour to an hour and a half undergound, measurements indicate that an extra 1.5 WLM would be incurred in a year. The results of the three methods of estimation are shown in the table, account being taken of all the surveys and separately of the major surveys. Results are rounded to the nearest 0.5 WLM.

Estimated exposures in second decade, WLM a year

\begin{tabular}{llll}
\hline Surveys & Mean & Weighted & Corrected \\
\hline All & 10.5 & 8.5 & 10.0 \\
Major & 11.5 & 9.5 & 11.0 \\
\hline
\end{tabular}

If one number is to be chosen to represent exposure in the mine during the second decade and especially the last few years of that decade a value of 10 WLM in a year is probably best. 
As for the first decade, our judgment is that exposures would have been somewhat higher because conditions underground have generally improved since mine owners have become aware of radiation hazards. ${ }^{89}$ It is not possible, however, to quantify this difference, and 10 WLM is put forward as a rough, but nevertheless defensible, estimate of the typical annual exposure over the whole period.

It is not possible to estimate the exposure of a particular individual, since the WL values vary from time to time and from place to place. Nevertheless, if an individual worked in various locations underground over an extended period, his exposure would tend to the typical value.

\section{Assessment}

We find, therefore, that the postmortem method suggests an annual exposure of $15 \pm 6 \mathrm{WLM}$ and the mine measurements about 10 WLM. These represent, on average, a cumulative exposure of about 270 WLM.

There are uncertainties in deducing exposure from measurements of lead-210 in bone. Some we have already mentioned, but others should be noted. The concentration of stable lead varies by about a factor of two in different bones, ${ }^{10}$ and one cannot assume that a particular lead- 210 value would be typical of the average skeletal concentration. There are also uncertainties about the deposition and subsequent metabolism of the radon decay products.

Nevertheless, this approach has been used to estimate the exposure of some uranium miners in the USA. Blanchard $e t a l^{1}$ illustrated that there was a clear relation between the concentration of radon decay products reported for the uranium mines and the concentration of lead-210 in samples of ribs and vertebrae from the miners. The investigators found more lead-210 than they predicted from a doubleexponential excretion function, ${ }^{11}$ and attributed the difference to the inhalation of the radon-222 gas and lead-210 itself in underground air and to the possibility that the cumulative exposure of some miners, in WLM, might have been underestimated. Eisenbud $e t$ $a l^{6}$ determined cumulative exposure both from invivo measurements of lead-210 in the skull and from measurements of radon decay products in mine air. In general, the exposure indicated by the measurement of lead-210 in bone was greater than that estimated from the air data, but the agreement was within a factor of two approximately. The discrepancy may have been attributable to the simplified metabolic model used, to differences in individual metabolism compared with the model, or to inadequacies in the air sampling data. In view of the uncertainties, agreement within a factor of two was considered reasonably good.

Against this background the correspondence of the estimates in our single case encourages us to view the lead-210 in bone method as a tenable means of retrospectively determining cumulative exposures to radon decay products above 100 WLM. This value accords with the exposure that a miner might accumulate under the present system of limitation. ${ }^{9}$ There are likely to be miners in the UK who have accumulated more but whose exposure histories are obscure: in such cases the lead in bone method might help to clarify matters.

We thank Mr G J Ham for his help with the initial preparation of the bone sample.

\section{References}

I Blanchard RL, Archer VE, Saccomanno G. Blood and skeletal levels of ${ }^{210} \mathrm{~Pb}-{ }^{210} \mathrm{Po}$ as a measure of exposure to inhaled radon daughter products. Health Phys 1969;16:585-96.

2 Fisher HL Jr. A model for estimating the inhalation exposure to radon-222 and daughter products from the accumulated lead210 body burden. Health Phys 1969;16:597-616.

${ }^{3}$ Snihs JO, Schnell PO, Soumela J. Some measurements on ${ }^{210} \mathrm{~Pb}$ in non-uranium miners in Sweden. In: Radiation protection in mining and milling of uranium and thorium. Bordeaux 9-11 Sept 1974. Geneva: International Labour Office, 1976:171-85.

4 United Nations Scientific Committee on the Effects of Atomic Radiation. Sources and effects of ionising radiation. New York: United Nations, 1977. (1977 Report to the General Assembly.)

5 United States Department of Environment. Environmental measurements laboratory procedures manual. New York: USDOE, 1972.

- Eisenbud M, Laurer GR, Rosen JC, Cohen N, Thomas J. In vivo measurement of lead-210 as an indicator of cumulative radon daughter exposure in uranium miners. Health Phys 1969;16: $637-46$.

7 International Commission on Radiological Protection.Report of the task group on reference man. Oxford: Pergamon Press, 1975. (ICRP publication 23.)

8 Strong JC, Laidlaw AJ, O'Riordan MC. Radon and its daughters in various British mines. Chilton: National Radiological Protection Board, 1975. (NRPB-R39.)

9 O'Riordan MC, Rae S. Thomas GH. Radon in British mines-a review. International conference on radiation hazards in mining: control, measurements and medical aspects. Colorado, New York: Society of Mining Engineers of the American Institute of Mining, Metallurgy and Petroleum Engineers Incorporated, October 1981.

${ }^{10}$ Holtzman RB. Measurement of the natural contents of RaD $\left({ }^{210} \mathrm{~Pb}\right)$ and $\mathrm{RaF}\left({ }^{210} \mathrm{Po}\right)$ in human bone-estimates of wholebody burdens. Health Phys 1963;9:385-400.

"Black SC, Archer VE, Dixon WC, Saccomanno G. Correlation of radiation exposure and lead-210 in uranium miners. Health Phys 1968;14:81-93. 